\title{
Cerebral haemodynamic effects of changes in positive end expiratory pressure in preterm infants
}

\author{
D B SHORTLAND,${ }^{*}$ D FIELD,${ }^{*}$ L N J ARCHER,${ }^{*} \mathrm{~N}$ A GIBSON,${ }^{*} \mathrm{~K}$ L WOODS, $\dagger$ D H EVANS, $\ddagger$ \\ AND M I LEVENE* \\ Departments of ${ }^{*}$ Child Health, †Pharmacology, and $¥$ Medical Physics, Leicester University Medical School
}

SUMMARY The effects of changes in positive end expiratory pressure (PEEP) on cerebral blood flow velocity, arterial blood gases, and mean arterial pressure were studied in newborn infants. In mechanically ventilated premature infants with severe respiratory disease, an increase in PEEP from 2 to $6 \mathrm{~cm} \mathrm{H}_{2} \mathrm{O}$ was associated with an increase in cerebral blood flow velocity. There was no significant change in mean arterial blood pressure. There was a significant increase in $\mathrm{PaO}_{2}$ and $\mathrm{PaCO}_{2}$ for every stepwise rise in PEEP. Multivariate regression analysis showed that $72 \%$ of the effect on cerebral blood flow velocity was attributable to $\mathrm{PaCO}_{2}$ alone and that any change in blood pressure was not likely to contribute to these changes. There was no evidence that changes in PEEP within the commonly used range adversely affected the neonatal cardiovascular or cerebral circulations.

The introduction of intermittent positive pressure ventilation (IPPV) has led to a large increase in the number of premature infants that survive the neonatal period, but the risk of sustaining perinatal cerebral lesions is increased in infants who are treated by mechanical ventilation. ${ }^{1}$ There has been considerable interest in the haemodynamic effects of IPPV in adults and ventilation can potentially influence the cerebral circulation in a number of ways, including by a direct effect on cardiac output, ${ }^{2-7}$ by increasing intracranial pressure,${ }^{89}$ or by reducing cerebral venous return. ${ }^{2} 8$

There is little information about the effects of respiratory support on cerebral haemodynamics in newborn babies, and the present study was designed to investigate the effect of different positive end expiratory pressures on cerebral blood flow velocity.

\section{Methods}

The study was performed in the neonatal unit at the Leicester Royal Infirmary between April 1987 and January 1988. All the babies entered into the study had idiopathic respiratory distress syndrome and at the time of the study they were in the acute phase of their disease and showing no clear signs of improvement. All the infants had indwelling arterial catheters in place. An infant was excluded if a pneumothorax was present, if a cerebral ultrasound scan showed any abnormality, or if the clinical condition was unstable. None of the infants was receiving any drug known to influence the cerebral circulation. The Leicestershire district ethical committee approved this study and informed consent was obtained from the parents before all studies. The variables that were measured are given below.

CEREBRAL BLOOD FLOW VELOCITY

Recordings of cerebral blood flow velocity were made from the anterior cerebral artery using an ATL duplex Doppler system with a 724A probe (pulse echo 7.5 MHz, Doppler frequency 5.0 Mhz). The artery was visualised in the sagittal plane with the probe over the infant's anterior fontanelle. The Doppler sample volume was positioned in the straight portion of the artery, midway between the origin of the anterior cerebral artery at the internal carotid artery and the most inferior part of the corpus callosum. The sample volume was set to 3 $\mathrm{mm}$ and the high pass filter to $100 \mathrm{~Hz}$. The signals from 25 to 30 consecutive cardiac cycles were recorded onto audiocassette tape and analysed off line through an Angioscan spectrum analyser. The maximum frequency envelope of the waveform was extracted and the velocity calculated from the wellknown Doppler equation. The artery was insonated at a point where the direction of blood flow was directly towards the transducer to minimise the error in the velocity calculation. The mean velocity over the cardiac cycle was derived by halving the maximum velocity. ${ }^{10}$ 
ARTERIAL BLOOD PRESSURE RECORDINGS

All the infants had direct arterial access either through an umbilical line positioned with its tip at the level of the diaphragm or through a radial line. The lines were attached by non-compliant tubing to a Gould pressure transducer with permanent write out onto a chart recorder. An observer recorded the mean arterial blood pressure immediately before the cerebral blood flow velocity recordings were made.

\section{AIRWAY PRESSURE RECORDINGS}

Ventilator pressures were recorded through a 19 gauge needle that was inserted into an endotracheal tube and then connected to a pressure transducer. The transducer signal was amplified and displayed using a Gould 4 channel recorder. Before each study the transducer was balanced and calibrated electronically.

It was thus possible to record pressure swings between peak inspiratory pressure and the positive end expiratory pressure (PEEP) directly at each stage of the study. In order to measure PEEP accurately it was necessary to open the ventilator circuit briefly; this permitted the pressure recorded by the transducer to drop to atmospheric.

Tidal volume was recorded so that the infants' respiratory pattern of interaction with the ventilator could be documented. This was done with a pneumotachograph (Gaeltec), integrator (Gould), and a differential pressure transducer (Gaeltec), in series with the ventilator. The pneumotachograph was placed between the endotracheal tube and the patient manifold of the ventilator. So that this addition to the ventilator circuit did not cause an unacceptable increase in the dead space, a flow of gas was created through the pneumotachograph as previously described. ${ }^{11}$ Volume data obtained were used only qualitatively to determine patterns of interaction.

At each study $0.2 \mathrm{ml}$ of blood was taken through the arterial line and the $\mathrm{PaCO}_{2}$ and the $\mathrm{PaO}_{2}$ tensions were determined.

\section{PROCEDURE}

The infants were studied at three PEEPs; low $(2 \mathrm{~cm}$ $\left.\mathrm{H}_{2} \mathrm{O}\right)$, intermediate $\left(4 \mathrm{~cm} \mathrm{H}_{2} \mathrm{O}\right)$, and high $(6 \mathrm{~cm}$ $\mathrm{H}_{2} \mathrm{O}$ ). Finally the PEEP was reset at $2 \mathrm{~cm} \mathrm{H}_{2} \mathrm{O}$ and the pump in the pneumotachograph circuit was removed. This was done to maintain a comparatively high $\mathrm{PaCO}_{2}$ so that a comparison could be made of the cerebral haemodynamics at the same PEEP but with different $\mathrm{PaCO}_{2}$ tensions. The peak inspiratory pressure was not altered between the recordings. A period of 10 minutes was allowed for stabilisation after each change in PEEP before a sequence of measurements was made. After each manoeuvre measurements were made of cerebral blood flow velocity, mean intra-arterial blood pressure, respiratory pattern, the peak inspiratory pressure and PEEP, as well as estimates of arterial $\mathrm{PaCO}_{2}$ and $\mathrm{PaO}_{2}$ tensions. At the end of the study the ventilator settings were returned to the positions they had been in before the study.

\section{STATISTICAL ANALYSIS}

The significance of differences between physiological variables at the three PEEPs were tested by the paired $t$ test. No adjustment of nominal $p$ value was made for multiple comparisons in view of the small number of groups compared.

Table Details of 17 infants studied, peak inspiratory pressure, and use of pancuronium at the time of study

\begin{tabular}{|c|c|c|c|c|c|}
\hline $\begin{array}{l}\text { Case } \\
\text { No }\end{array}$ & $\begin{array}{l}\text { Gestation } \\
\text { (weeks) }\end{array}$ & $\begin{array}{l}\text { Birthweight } \\
(g)\end{array}$ & $\begin{array}{l}\text { Age (hours) } \\
\text { at time of } \\
\text { study }\end{array}$ & $\begin{array}{l}\text { Peak inspiratory } \\
\text { pressure }(\mathrm{mm} \mathrm{Hg})\end{array}$ & $\begin{array}{l}\text { Pancuronium } \\
\text { used during } \\
\text { study }\end{array}$ \\
\hline 1 & 28 & 910 & 108173 & $17 \cdot 7,17 \cdot 7$ & No, no \\
\hline 2 & 31 & 1520 & $15 \quad 108$ & $25 \cdot 8,17 \cdot 0$ & Yes, no \\
\hline 3 & 28 & 1330 & $100 \quad 173$ & $21 \cdot 4,19 \cdot 7$ & Yes, yes \\
\hline 4 & 27 & 990 & 329 & $20 \cdot 0$ & No \\
\hline 6 & 33 & 1570 & 120 & $34 \cdot 6$ & No \\
\hline 7 & 29 & 1500 & 49 & $31 \cdot 0$ & Yes \\
\hline 8 & 28 & 1090 & 25 & $21 \cdot 7$ & No \\
\hline 9 & 31 & 1830 & 16 & $28 \cdot 5$ & No \\
\hline 10 & 31 & 1280 & 68 & $16 \cdot 0$ & Yes \\
\hline 11 & 27 & 730 & 98 & $22 \cdot 0$ & No \\
\hline 12 & 32 & 1860 & 96 & $21 \cdot 8$ & No \\
\hline 13 & 32 & 1470 & 85 & $25 \cdot 0$ & Yes \\
\hline 15 & 35 & 2320 & 46 & $29 \cdot 2$ & Yes \\
\hline 16 & 29 & 1080 & 12 & $25 \cdot 7$ & No \\
\hline 17 & 37 & 4400 & 92 & 29.9 & No \\
\hline
\end{tabular}


The dependence on cerebral blood flow velocity on $\mathrm{PaCO}_{2}, \mathrm{PaO}_{2}$, and mean arterial blood pressure was examined by multivariate regression. The suitability of the linear model was confirmed by the use of residual plots. The additional effect of PEEP was then examined by inclusion of dummy variables representing different PEEPs.

\section{Results}

Seventeen infants were studied on 20 occasions. The median gestation was 28.5 weeks (range 24-37) and the median birth weight was $1330 \mathrm{~g}$ (range 730 to $4400)$. The median age at the time of the study was 88.5 hours (range 9 to 329). Seven studies were performed while the infants were receiving pancuronium for neuromuscular paralysis. Details of the infants are shown in the table.

The PEEP measured directly from the airway differed in some cases from the ventilator manometer dial. The actual median PEEP at the low level $(\mathrm{n}=17)$ was $2.2 \mathrm{~cm}$ (range 0 to 6$)$, at the intermediate level $4 \mathrm{~cm}$ (range $2 \cdot 4$ to $6 \cdot 1$ ), and at the high level $6.8 \mathrm{~cm}$ (range 3.4 to 8.5 ). Despite these variations every infant showed a sequential increase in the particular level of PEEP as planned.

The changes in $\mathrm{PaO}_{2}$ and $\mathrm{PaCO}_{2}$ with increasing levels of PEEP are shown in fig 1. The mean (SEM) increase in the $\mathrm{PaCO}_{2}$ between the studies at low and intermediate PEEP was $0.7(0 \cdot 17) \mathrm{kPa}$, and

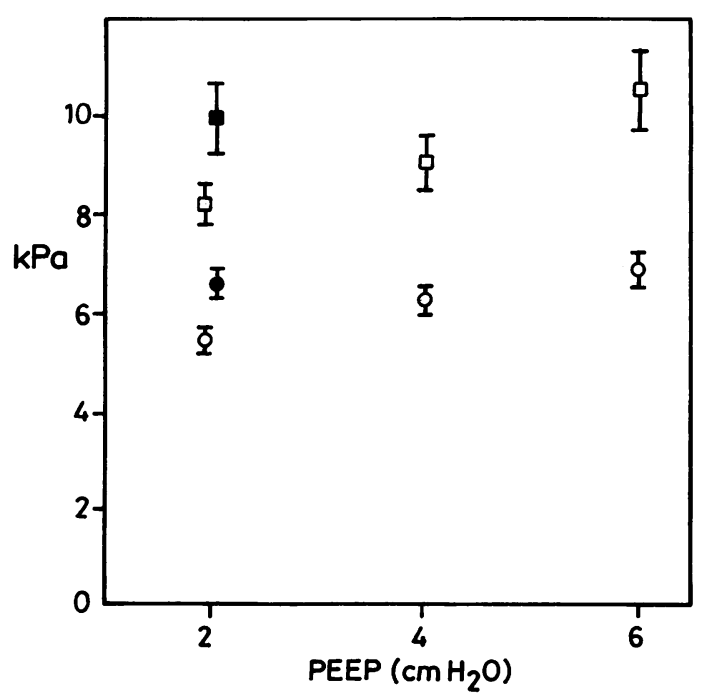

Fig 1 Effect of PEEP with (open symbols) and without (closed symbols) the pump in circuit on $\mathrm{PaO}_{2}$ (squares) and $\mathrm{PaCO}_{2}$ (circles). Points are means (SEM). between low and high PEEP was $1.3(0.27) \mathrm{kPa}$. These changes were significant $(\mathrm{p}<0.001$ on both occasions). The mean increase in $\mathrm{PaCO}_{2}$ between the studies at $2 \mathrm{~cm}$ of PEEP with and without the pump was $1.2(0.23) \mathrm{kPa}(\mathrm{p}<0.001)$.

The mean increase in $\mathrm{PaO}_{2}$ between low and intermediate PEEP was $0.9(0.41) \mathrm{kPa}$, and between low and high PEEP $2.8(0.74) \mathrm{kPa}$. These changes were significant $(\mathrm{p}<0.04$ and $<0.002$, respectively). There was a significant increase of $1.6(0.53) \mathrm{kPa}$ in the $\mathrm{PaO}_{2}$ between the studies at $2 \mathrm{~cm}$ with and without the pump $(\mathrm{p}<0.01)$.

The changes in cerebral blood flow velocity and mean arterial blood pressure with different levels of PEEP are shown in fig 2. The mean increase in cerebral blood flow velocity from the anterior cerebral artery between the studies at low and intermediate PEEP was $2 \cdot 1(0 \cdot 81) \mathrm{cm} / \mathrm{s}$, and between low and high PEEP $4.2(1.00) \mathrm{cm} / \mathrm{s}$. The increase was significant on both occasions $(\mathrm{p}<0.025$ and $<0 \cdot 001$, respectively). The mean increase between the studies at low PEEP with and without the pump was $3.4 \mathrm{~cm} / \mathrm{s}(0.92)(\mathrm{p}<0.005)$.

The mean increase in arterial blood pressure between low and intermediate PEEP was $1 \cdot 2(1 \cdot 07)$ $\mathrm{mm} \mathrm{Hg}$. The increase in arterial blood pressure

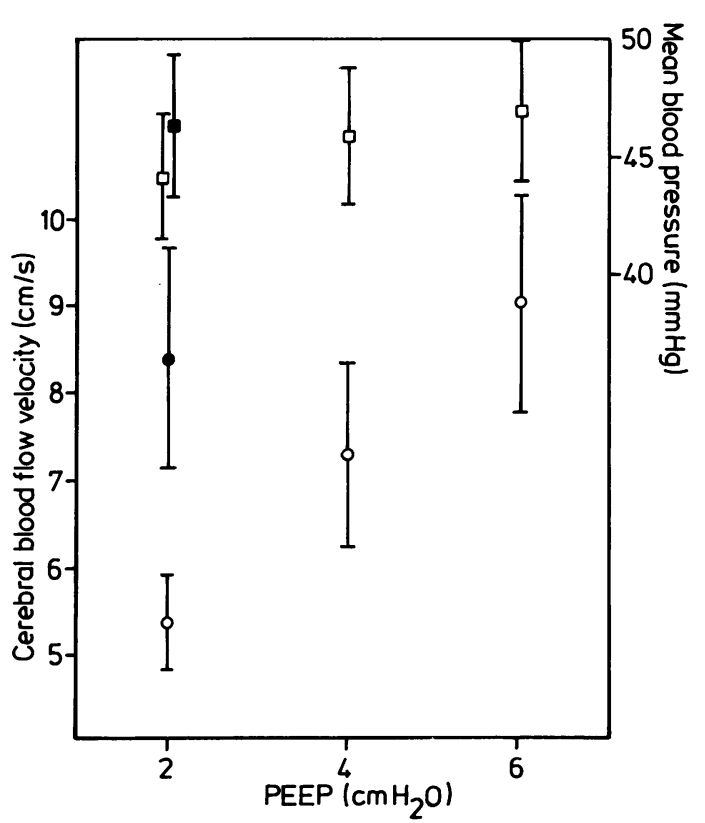

Fig 2 Effect of PEEP with (open symbols) and without (closed symbols) the pump in circuit on mean arterial blood pressure (squares) and cerebral blood flow velocity. Points are means (SEM). 


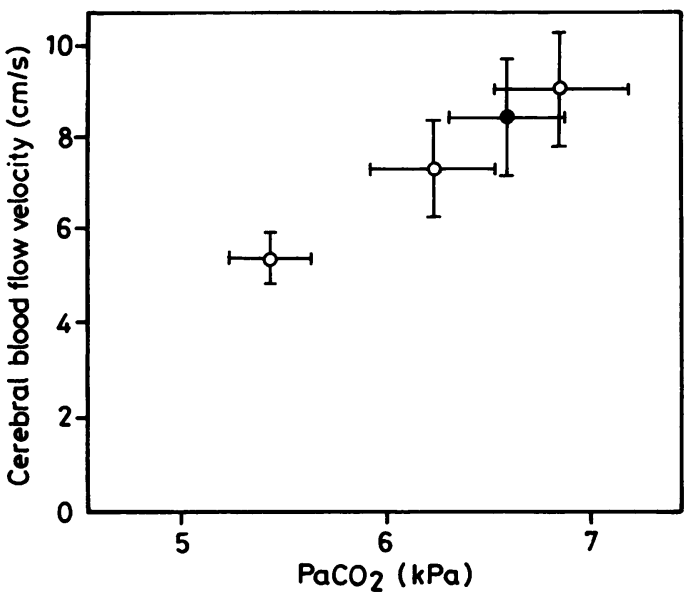

Fig 3 Association between cerebral blood flow velocity and $\mathrm{PaCO}_{2}$. Points are means (SEM) and represent readings at three settings of PEEP with (open circles) and without (closed circles) pump in circuit.

between low and high PEEP was $1.8(1.52) \mathrm{mm} \mathrm{Hg}$, and between the studies at low PEEP with and without the pump was $2 \cdot 25(1 \cdot 17) \mathrm{mm} \mathrm{Hg}$. None of these changes was significant.

A multivariate regression analysis was carried out to investigate the dependence of cerebral blood flow velocity on the potential explanatory variables: $\mathrm{PaCO}_{2}, \mathrm{PaO}_{2}$, blood pressure, and PEEP. The analysis showed that there was a significant association between cerebral blood flow velocity and $\mathrm{PaCO}_{2}(\mathrm{p}<0.001)$ and $\mathrm{PaO}_{2}(\mathrm{p}<0.02)$. Of the variation in cerebral blood flow velocity, $80 \%$ was attributable to the changes in $\mathrm{PaCO}_{2}$ and $\mathrm{PaO}_{2}$ (Rsq adjusted $=80 \%$ ), and $71.5 \%$ of the variation was attributable to $\mathrm{PaCO}_{2}$ alone. There was no improvement in the model when blood pressure was incorporated. The coefficient of mean arterial blood pressure when added to $\mathrm{PaCO}_{2}$ and $\mathrm{PaO}_{2}$ was not significant $(p=0.7)$. The inclusion of PEEP in the multivariate analysis did not improve the explanatory model $(p>0.9)$ and we concluded that an increase in PEEP between the levels of 2 and $6 \mathrm{~cm}$ did not have a direct effect on the cerebral circulation.

The pneumotachograph recordings showed the pattern of interaction between the infants' spontaneous breaths and the ventilators in those infants who were not paralysed. In none of these infants did the pattern change significantly among the settings of PEEP, and we therefore assumed that the infants' arousal states had not changed significantly between the studies.

\section{Discussion}

We have shown that increasing PEEP to $6 \mathrm{~cm} \mathrm{H}_{2} \mathrm{O}$ causes a rise in cerebral blood flow velocity, and it is likely that this change is mediated by alterations in blood gas tensions. Doppler assessments of cerebral haemodynamics measure the velocity of blood flow and not volumetric flow, but a number of investigators have shown a close correlation between cerebral blood flow velocity and volumetric assessment of cerebral blood flow in newborn animals ${ }^{12}{ }^{13}$ and in human infants. ${ }^{14} \mathrm{We}$ believe, therefore, that cerebral blood flow increased when PEEP was increased between these settings.

There have been few studies of the effects of changes in IPPV on the cerebral circulation in human infants. Ellison and Denny ${ }^{15}$ found that the mean cerebral blood flow velocity was significantly reduced in infants receiving ventilation, and Cowan and Thoresen $^{16}$ found that the peak inspiratory pressure affected the Doppler arterial waveform in a proportion of newborn infants who required ventilation. Leahy et al ${ }^{17}$ showed that an increase in cranial blood volume occurred in infants who required mechanical ventilation compared with those that were breathing spontaneously.

We have shown that cerebral blood flow velocity increases as PEEP increases. From the multivariate analysis it seems that the increase in $\mathrm{PaCO}_{2}$ between the levels of PEEP was the most important factor in determining the cerebral blood flow velocity. This is perhaps not surprising, as carbon dioxide is a potent stimulator of cerebral blood flow in premature infants. ${ }^{18}$ We have previously reported that increases in $\mathrm{PaCO}_{2}$ cause pronounced increases in cerebral blood flow velocity even in the most immature infants. ${ }^{19}$ and that hyperoxia also produces increases in cerebral blood flow velocity though to a lesser extent. ${ }^{20}$

An increase in the airway pressure can compromise cardiac function in a number of ways. Morgan $e t$ $a l^{2}$ concluded that the most important haemodynamic effects of positive pressure ventilator treatment were an increase in the intrathoracic pressure with a reduction in venous return to the heart. Aidinis $e t$ $a l^{8}$ thought that this increase in intrathoracic pressure would increase intracranial pressure and reduce systemic blood pressure. The combination of these effects would reduce cerebral perfusion pressure and have potentially disastrous consequences for premature infants' brains. Cardiac function could be further compromised by increases in pulmonary vascular resistance as the alveoli become distended by increasing levels of PEEP, this would increase the resistance to blood flow within the lungs, and cause reduced left ventricular dimensions by over- 
loading the volume in the right ventricle. ${ }^{4}$ Although we did not measure cardiac output we did not find a significant fall in the blood pressure as PEEP was increased, and our results suggest that levels of PEEP used in the management of respiratory illness in neonates do not produce serious functional effects on cardiac output.

When considering the effects of PEEP we have analysed the results according to whether the level was low, intermediate, or high, and we have looked at the change in the variables between the settings. We have not considered absolute levels of PEEP as it is clear that the effect of PEEP on the cardiovascular or cerebral circulations in any particular infant will be greatly modified by the compliance of the lung. ${ }^{6}$ The pressure transducer connected to the infant's airway did, however, enable us to check that increasing the PEEP settings on the ventilator did result in an increase in the airway pressure. Unfortunately it was not possible to measure lung compliance and we accept that these conclusions may not be relevant to all infants with lung disease. Most of the infants had moderate to severe respiratory distress syndrome and presumably poorly compliant lungs, and hence were comparatively resistant to alveolar distension resulting from increases in airway pressure.

In conclusion, increasing levels of PEEP cause significant increases in arterial blood gas tensions, and it is these changes that increase cerebral blood flow velocity. There is no evidence that levels of PEEP up to $6 \mathrm{~cm} \mathrm{H}_{2} \mathrm{O}$ reduce cerebral blood flow.

\section{References}

1 Levene MI, Fawer C-L, Lamont RF. Risk factors in the development of intraventricular haemorrhage in the preterm neonate. Arch Dis Child 1982;57:410-7.

2 Morgan BC, Martin WE, Hornbeam TF, Crawford EW, Guntheroth WG. Haemodynamic effects of intermittent positive pressure ventilation. Anaesthesiology 1966;27:584-90.

${ }^{3}$ Qvist J, Pontoppidan H, Wilson RS, Lowenstien E, Laver MB. Haemodynamic responses to mechanical ventilation with PEEP. Anesthesiology 1975;42:45-55.

${ }^{4}$ Jardin F, Farcot JC, Boisante L, Curien N, Margairaz A, Bourdarias JP. Influence of positive end expiratory pressure on left ventricular performance. $N$ Engl J Med 1981;304:387-92.
${ }^{5}$ Santamore WP, Heckman JL, Bove AA. Cardiovascular changes from expiration to inspiration during IPPV. Am J Physiol 1983;245:H307-12.

${ }^{6}$ Mirro R, Busija D, Green R, Leffler C. Relationships between airway pressure, cardiac output and organ blood flow with normal and decreased respiratory compliance. $J$ Pediatr 1987;111:101-6.

${ }^{7}$ Hausdorf G, Hillwege HH. Influence of positive end-expiratory pressure on cardiac performance in premature infants: A Doppler-echocardiographic study. Crit Care Med 1987;15: 661-4.

${ }^{8}$ Aidinis SJ, Laferty J, Shapiro HM. Intracranial responses to PEEP. Anesthesiology 1976;45:275-86.

${ }^{9}$ Huseby JS, Pavlin EG, Butler J. Effect of positive end expiratory pressure on intracranial pressure in dogs. $J$ Appl Physiol 1978;44:25-7.

10 Evans DH. On the measurement of mean velocity of blood over the cardiac cycle using Doppler ultrasound. Ultrasound Med Biol 1985;11:735-41.

11 Field D, Milner AD, Hopkin IE. High and conventional rates of positive pressure ventilation. Arch Dis Child 1984;59:1151-4.

12 Batton DG, Hellmann J, Hernandez MJ, Maisels MJ. Regional blood flow cerebral blood velocity and pulsatility index in newborn dogs. Pediatr Res 1983;17:908-12.

${ }^{13}$ Hansen NB, Stonestreet BS, Rosenkrantz TS, Oh W. Validity of Doppler measurements of anterior cerebral artery blood flow velocity: correlation with brain blood flow in piglets. Pediatrics 1983;72:526-31.

14 Grieson G, Johnsen K, Ellison PH, Fredriksen PS, Mali J, FriisHanson B. Cerebral blood flow in the newborn infant: comparison of Doppler ultrasound and 133 Xenon clearance. J Pediatr 1984;104:411-7.

15 Ellison P, Denny J. Doppler measures of cerebral blood flow: respirator settings and blood gases in the neonatal intensive care unit. Ann Neurol 1984;12:216-7.

16 Cowan F, Thoresen M. The effects of intermittent positive pressure on the cerebral arterial and venous velocities in the newborn infant. Acta Paediatr Scand 1987;76:239-47.

17 Leahy FAN, Cates D, MacCallum M, Rigato $\mathrm{H}$. Effect of $\mathrm{CO}_{2}$ and $100 \% 02$ on cerebral blood flow in preterm infants. $J$ Appl Physiol 1980;48:468-72.

${ }_{18}$ Greisen $\mathrm{G}$, Trojaborg W. Cerebral blood flow, $\mathrm{PaCO}_{2}$ changes and visual evoked potentials in mechnically ventilated, preterm infants. Acta Paediatr Scand 1987;76:394-400.

19 Levene MI, Shortland D, Gibson N, Evans DH. Carbon dioxide reactivity of the cerebral circulation in extremely premature infants: effects of postnatal age and indomethacin. Pediatr Res 1988;24:175-9.

20 Niijima S, Shortland DB, Levene MI, Evans DH. Transient hyperoxia and cerebral blood flow velocity in infants born prematurely and at full term. Arch Dis Child 1988;63:1126-30.

Correspondence to Professor MI Levene, Department of Child Health and Paediatrics, The General Infirmary, Leeds LS1 3EX.

Accepted 26 October 1988 